\title{
Recognition of Amino Acids by Membrane Potential of Immobilized Serum Albumin Membranes
}

\author{
Akon Higuchi, ${ }^{\dagger}$ Yoshikazu Ando, Norihiko Minoura, $^{*}$ \\ and Tsutomu NAKAGAWA \\ Department of Industrial Chemistry, School of Science and Technology, \\ Meiji University, 1-1-1 Higashi-mita, Tama-ku, Kawasaki, \\ Kanagawa 214, Japan \\ * National Institute of Materials and Chemical Research, \\ 1-1 Higashi, Tsukuba, Ibaraki 305 Japan
}

(Received January 27, 1993)

\begin{abstract}
The shifts in membrane potential, caused by the injection of some amino acids into a permeation cell, were measured using immobilized serum albumin membranes. The shift in the observed membrane potential apparently was considered to consist of shifts in the membrane potential originating from (a) $\mathrm{pH}$ changes in the cell and (b) changes of the fixed charge density in the membrane due to the binding between the amino acids and the serum albumin. The intrinsic shifts in the membrane potential were observed to increase in the following order, D-glucose $=$ methyonine $=0<$ D-serine $<$ L-tryptophan $<$ L-serine $<$ D-tryptophan $<$ isoleucine $<$ L-alanine $<\mathrm{D}$-alanine. The $t_{3 / 4}$ value was found to increase in the following order, D-alanine $<$ serine $<$ L-alanine $<$ tryptophan, where $t_{3 / 4}$ indicates the time at which shows $75 \%$ of the apparent shifts in the membrane potential. The membrane potential theory provides satisfactory explanations for the apparent shifts and intrinsic shifts caused by the binding between the amino acid and the serum albumin which were obtained experimentally.

KEY WORDS Membrane / Membrane Potential / Serum Albumin /

Recognition / Amino Acid /
\end{abstract}

Electrical pulses in living organisms (shifts of membrane potential in living membrane or nerve fibers) are directly generated at internal receptors that perceive chemical substrates such as hormones, neurotransmitters ${ }^{1}$ or bitter and sweet substrates ${ }^{2}$. Artificial bilayer membranes which do not contain the receptors have also been studied as excitable models of living membranes $^{3,4}$.

The membrane potential induced by the products in the reaction between enzymes and specific substrates in immobilized enzyme membranes has been investigated for the development of biosensors by several researchers. ${ }^{5-8}$ Aizawa et al. $^{9}$ have also developed an immunoresponsive membrane for serological tests for syphilis; wherein the antibody concentration was determined by monitoring the membrane potential.

In our previous studies, the shifts in the membrane potential, caused by the injection of substrates into a permeation cell, were measured using immobilized glucose oxidase membranes. ${ }^{10,11}$ No shift in the membrane potential was observed with the injection of caffeine and galactose; however, there was a shift for D- and L-glucose. Since the enzyme did not react with $\mathrm{L}$-glucose but did react with D-glucose, it was suggested that L-glucose can bind with the enzyme but cannot react with the enzyme; therefore, no product is produced ${ }^{10}$.

The shifts in membrane potential were

\footnotetext{
+ Present address: Department of Industrial Chemistry, Seikei University, 3-3-1 Kitamachi Kichijoji, Musashino,
} Tokyo 180, Japan. 


\section{A. Higuchl et al.}

considered to be generated by a change in the charge density in the enzyme membrane because of the binding of glucose to the enzyme. This induces a conformational change in the enzyme (induced fit of the enzyme ${ }^{12}$ ) and leads to a change in the charge density.

The previous studies prompted us to investigate the potential response of immobilized protein (except enzyme) membranes induced by specific substrates; this response does not generate a product. The shifts in the membrane potential are generated by a change in the charge density in the membrane due to the binding of substrates to the protein in this system. The serum albumin is known to serve as the transport protein and to have a high affinity for various substrates such as bilirubin, L-tryptophan, hormones and warfarin. ${ }^{13,14}$ These substrates bind to serum albumin reversibly, and a limited number of binding regions of different specificity is known to exist.

In this study, bovine serum albumin was immobilized (entrapped) in a poly $(\alpha$-amino acid) network, and the shifts in the membrane potential caused by the injection of some amino acids were investigated.

\section{EXPERIMENTAL}

\section{Materials}

Poly( $\gamma$-methyl-L-glutamate), PMLG, was kindly supplied by Ajinomoto Co., Inc. and purified by precipitation from $5 \mathrm{wt} \%$ dichloroethane in methanol. Bovine serum albumin (CRG-7, fatty acid free type) was purchased from Nakarai Tesque, Inc. (Kyoto, Japan). Other chemicals were of reagent grade and were used without further purification. Ultrapure water by the Toraypure LV-10T system (Toray Co., Ltd.) was used throughout the experiments.

\section{Immobilized Protein Membranes}

Bovine serum albumin (BSA) was dissolved in a $1 \mathrm{wt} \%$ dichloroethane solution of PMLG. The casting solution used in this study had a BSA concentration of $4.0 \mathrm{mg} \mathrm{cm}^{-3}$ PMLG solution. Immobilized (entrapped) BSA membranes were prepared by casting the BSAPMLG solution onto flat Petri dishes and then drying at room temperature for 6 days. The BSA-PMLG membranes were finally dried under vacuum at room temperature for $24 \mathrm{~h}$ and then stored at $10^{\circ} \mathrm{C}$.

\section{Measurement of Membrane Potential}

The membrane potential, $\Delta \phi$, was determined in cells which consisted of two chambers separated by the membrane. A schematic diagram of apparatus is shown in Figure 1. Each chamber contained $150 \mathrm{~cm}^{3}$ of aqueous $\mathrm{NaCl}$ solution, and the concentration of the

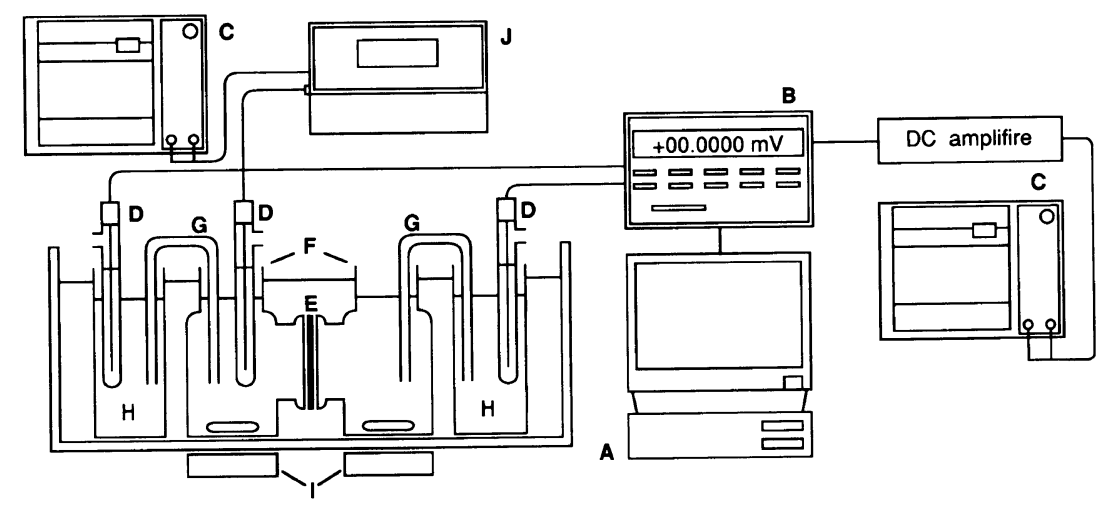

Figure 1. Schematic diagram of apparatus: A, personal computer; B, digital multimeter; C, recorder; D, electrode; E,membrane; F, permeation cell; $\mathrm{G}$, salt bridge; $\mathrm{H}, 3 \mathrm{~mol} \mathrm{dm}{ }^{-3} \mathrm{KCl}$ solution; I, stirrer; J, $\mathrm{pH}$ meter. 
solution was kept constant in one side of the chamber (side 1 ), $C_{1}$, at $1.0 \times 10^{-3} \mathrm{~mol} \mathrm{dm}^{-3}$ and was changed in the other side of the chamber (side 0 ), $C_{0}$, from $1.0 \times 10^{-4} \mathrm{~mol}$ $\mathrm{dm}^{-3}$ to $1.0 \mathrm{~mol} \mathrm{dm}{ }^{3} \cdot{ }^{10,11,15,16}$ An effective membrane area was $6.8 \mathrm{~cm}^{2}$. The potential was measured using a digital multimeter (range -99.9999 mV +99.9999 mV, model 7561, Yokogawa Electronic Co.) with $\mathrm{Ag} / \mathrm{AgCl}$ electrodes (TOA HS-205C, TOA Electronics Ltd.) at $37 \pm 0.02^{\circ} \mathrm{C}$.

The $\mathrm{pH}$ in the cell was also monitored with a $\mathrm{pH}$ meter (TOA HM-30S, TOA Electronics Ltd.). The membrane potential and its shift were measured when the $\mathrm{pH}$ in the cell indicated a constant value of \pm 0.01 for the $\mathrm{pH}$ variation after $20 \mathrm{~min}$.

\section{Measurement of Shifts in Membrane Potential}

After the $\mathrm{pH}$ in the cell registered a constant value $(\mathrm{pH} 5.48 \pm 0.23)$, powders of the amino acids were carefully and quickly injected into the chamber of side 1 . The powders of amino acids were injected into the chamber (i.e., powder-injection method) instead of the solution of amino acids (i.e., solution-injection method $^{10,11)}$ in this study. It takes $20 \mathrm{~s}$ for amino acids except tryptophan to be dissolved in water at $C_{\mathrm{s}}$ (concentration of injected substrate in the cell of side 1) $\leq 0.1 \mathrm{~mol} \mathrm{dm}^{-3}$ and $90 \mathrm{~s}$ for tryptophan to be dissolved in water at $C_{\mathrm{s}}=0.01 \mathrm{~mol} \mathrm{dm}^{-3}$, while it takes $15 \mathrm{~s}$ until the solution is injected into the chamber completely by using a funnel in the solutioninjection method. There is, therefore, no significant difference whether the solution of amino acid is injected into the cell ${ }^{10,11}$ or the powder of amino acid is injected into the cell. Since the experiments on the condition of high $C_{\mathrm{s}}$ can be performed in the powder-injection method, the powder of amino acid was injected into the cell in this study.

The (apparent) shift in the membrane potential, caused by the injection of the amino acid into the cell, was monitored on a recorder and the data were transferred to a 16-bit per- sonal computer (PC-9801VX, NEC Corp.). The shift of the $\mathrm{pH}$ was also monitored in this study.

The solution in the cell was replaced with ultrapure water several times after the measurements to remove the residual amino acids. Each of the membranes can withstand measurements of more than 30 times over a period of one month. However, compared to the initial shifts of the membrane potential an $8-9 \%$ decrease in the shifts was observed for the membranes used 30 times. The membranes used in this study satisfied the condition that potential variation was within $\pm 0.2 \mathrm{mV}$ at a constant $\mathrm{pH}$ before the injection of substrates. The membrane potential shifts were reproducible to within $c a$. $\pm 1.8 \mathrm{mV}$ on repeated runs with the same or different membranes. Each point in Figures 4-7 was an average of 3 or 4 measurements unless otherwise noted.

\section{RESULTS AND DISCUSSION}

\section{Changes in Membrane Potential}

Changes in the membrane potential upon the injection of L-alanine at $C_{\mathrm{s}}=0.01 \mathrm{M}$ were measured for PMLG and BSA-PMLG membranes, where $C_{s}$ is the concentration of injected substrate in the cell of side 1 . The results are shown in Figure 2. The shifts in

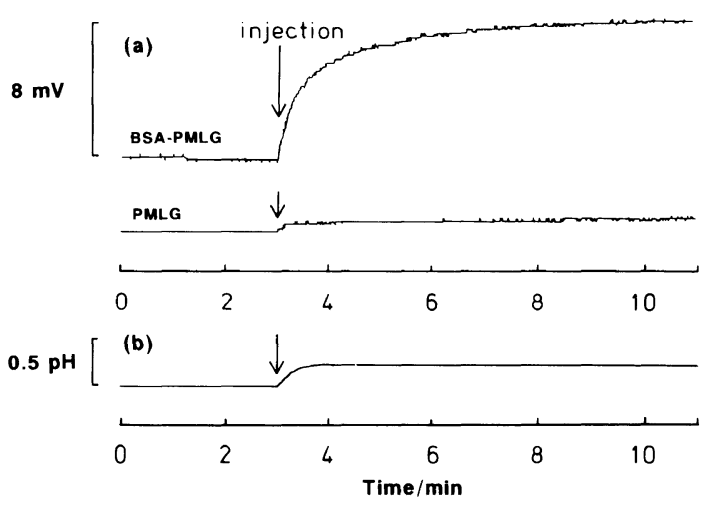

Figure 2. Time course of the membrane potential change (a) and the $\mathrm{pH}$ change (b) on the injection of L-alanine in the BSA-PMLG membrane and the PMLG membrane at $C_{0}=0.1 \mathrm{moldm}^{-3}, C_{\mathrm{s}}=0.01 \mathrm{~mol} \mathrm{dm}^{-3}$ and $37^{\circ} \mathrm{C}$. 


\section{A. Higuchi et al.}

membrane potential, $\Delta \Delta \phi_{\text {app }}$, defined by the difference in the potential before and after the injection of substrates in equilibrium were observed to be $0.96 \mathrm{mV}$ for the PMLG membrane and $8.52 \mathrm{mV}$ for the BSA-PMLG membrane in this case. Apparently high shifts in the membrane potential were observed for the BSA-PMLG membrane compared to the PMLG membrane having no specific binding sites for substrates. Upon the injection of L-alanine, both the change in the membrane potential and the $\mathrm{pH}$ change in the cells of side 0 and side 1 were measured. The results are shown in Figure 2. The $\mathrm{pH}$ did not change in the cell of side 0 for either the PMLG or the BSA-PMLG membranes. This is due to the fact that the permeability of substrates through the PMLG and the BSA-PMLG membranes is extremely low (e.g., the permeability ${ }^{20}$ of $\mathrm{NaCl}$ through PMLG membrane is $10^{-11} \mathrm{~cm}^{2} \mathrm{~s}^{-1}$, and the permeability of L-alanine through PMLG could not be measured because of its low permeability). However, a shift in the $\mathrm{pH}$ of 0.21 was observed in the cell of side 1 (the side where the substrate is injected) for both the PMLG and the BSA-PMLG membranes. The shift of the $\mathrm{pH}$ in the cell does not depend on the membranes used but depends on the substrate and the amount of it injected into the cell. This is due to the fact that the isoelectric point of L-alanine ( $\mathrm{pH}$ 6.00) is slightly higher than the $\mathrm{pH}$ in the cell before the injection of L-alanine $(\mathrm{pH} 5.55$ in this case, this is due to the existence of $\mathrm{CO}_{2}$ in the cell originated from $\mathrm{CO}_{2}$ in atmosphere), and the $\mathrm{pH}$ in the cell will approach the isoelectric point.

\section{Intrinsic Shifts}

The shift in the observed membrane potential apparently $\left(\Delta \Delta \phi_{\text {app }}\right)$ is considered to consist of shifts in membrane potential originating from (a) $\mathrm{pH}$ changes in the cell and (b) changes of the fixed charge density in the membrane due to the binding between BSA and the substrate. ${ }^{10,11}$ The object of this study is to

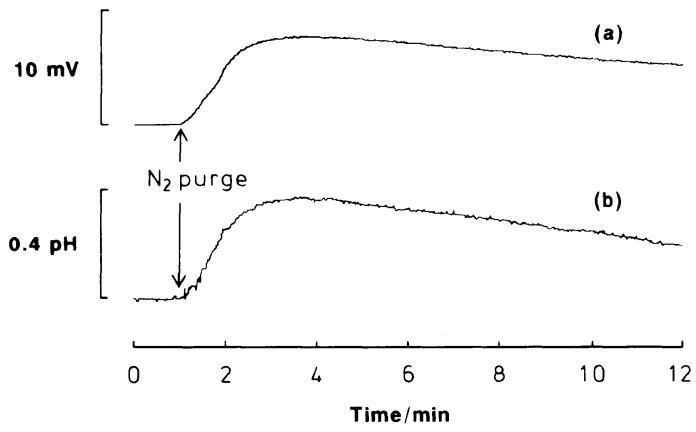

Figure 3. Time course of the membrane potential change (a) and the $\mathrm{pH}$ change (b) induced by $\mathrm{N}_{2}$ bubbling in the cell of side 1 at $C_{0}=0.1 \mathrm{~mol} \mathrm{dm}{ }^{-3}$ and $37^{\circ} \mathrm{C} . \mathrm{N}_{2}$ bubbling was performed from $1 \mathrm{~min}$ to $3 \mathrm{~min}$.

obtain the intrinsic shift in the membrane potential $\left(\Delta \Delta \phi_{\text {int }}\right)$ of the BSA-PMLG membranes due to the binding between BSA and the substrate. Therefore, the effect of the membrane potential change on the $\mathrm{pH}$ change in the cell was investigated at first and is shown for the BSA-PMLG membrane in Figure 3. The real time response of the membrane potential change was observed for the BSAPMLG membrane. When the $\mathrm{pH}$ of the cell was increased by $\mathrm{N}_{2}$ bubbling into the cell to remove $\mathrm{CO}_{2}$, exactly the same tendency was also observed for the PMLG membrane with the exception of the absolute value of the potential change. Therefore, the dependence of shifts in the membrane potential on $\mathrm{pH}$ shifts can be measured for both the PMLG and the BSA-PMLG membranes at $C_{0}=0.1 \mathrm{~mol}$ $\mathrm{dm}^{-3}$. These data are summarized in Figure 4. It was found that the shifts in membrane potential are linearly related to the $\mathrm{pH}$ shifts (e.g., the square of correlation coefficient $\left(r^{2}\right)=0.986$ for the PMLG membrane and $\mathrm{r}_{2}=0.997$ for the BSA-PMLG membrane).

Therefore, the intrinsic shifts in membrane potential $\left(\Delta \Delta \phi_{\text {int }}\right)$ can be obtained from $\Delta \Delta \phi_{\text {app }}$ minus $\Delta \Delta \phi$ caused by $\mathrm{pH}$ shifts, $\Delta \Delta \phi_{\mathrm{pH}} \cdot \Delta \Delta \phi_{\mathrm{pH}}$ can be estimated from the calibration curves shown in Figure 4. The dependence of the intrinsic shifts in the membrane potential on the concentration of L-alanine injected in the 


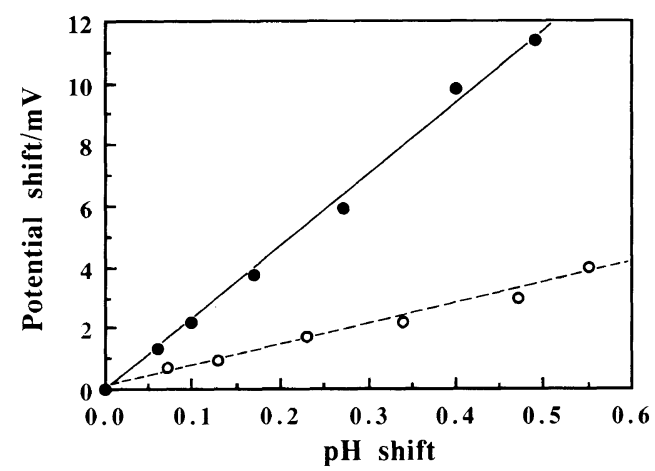

Figure 4. Dependence of shifts in the membrane potential on the $\mathrm{pH}$ shifts for the PMLG $(O)$ and the BSA-PMLG (O) membranes at $C_{0}=0.1 \mathrm{~mol} \mathrm{dm}^{-3}$ and $37^{\circ} \mathrm{C}$.

cell was calculated in this way for the PMLG membrane and the BSA-PMLG membrane, and this is shown in Figure 5. No intrinsic shift in the membrane potential was observed for the PMLG membrane; however, the intrinsic shift was surely observed for the BSA-PMLG membrane. The shifts in membrane potential were also reported on the injection of glucose into the cell for the glucose oxidase-PMLG membrane in the previous study. ${ }^{10,11}$ Therefore, the specific binding between the host and the guest molecules in the membrane may be important for observation of the shifts in the membrane potential, because no intrinsic shift in the membrane potential was observed for the PMLG membrane. The site saturation mechanism, where L-alanine binds to BSA in the BSA-PMLG membrane, is expected as depicted in Figure 5, since $\Delta \Delta \phi_{\text {int }}$ can be satisfactorily explained by eq 1 .

$$
\frac{1}{\Delta \Delta \phi_{\text {int }}}=\frac{A}{C_{\mathrm{s}}}+B
$$

$\mathrm{A}$ and $\mathrm{B}$ are selected to be 0.003016 and 0.08075 from the best fitting using the linear least square method, and the correlation coefficient is obtained to be 0.999 at $C_{\mathrm{s}}>0.005 \mathrm{~mol} \mathrm{dm}^{-3}$ in this study. It is, therefore, suggested that $\Delta \Delta \phi_{\text {int }}$ increases with the increase of bound amino acid on BSA in the BSA-PMLG

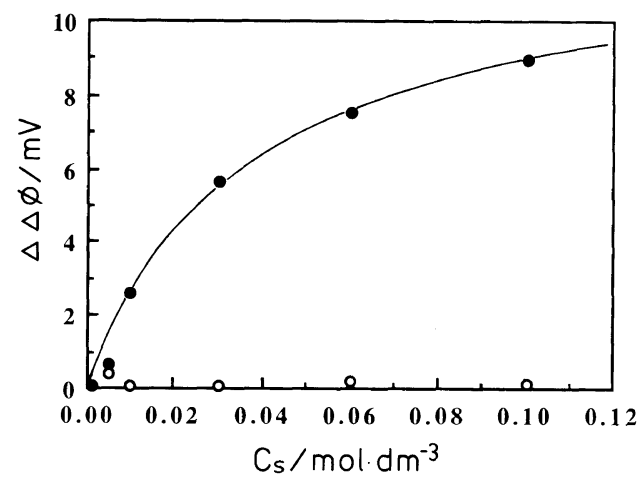

Figure 5. Concentration $\left(C_{\mathrm{s}}\right)$ dependence of intrinsic shifts in the membrane potential for the PMLG $(O)$ and the BSA-PMLG $(\bigcirc)$ membranes at $C_{0}=0.1 \mathrm{~mol} \mathrm{dm}^{-3}$ and $37^{\circ} \mathrm{C}$. Solid line is calculated from eq 1 with $A=0.003016$ and $B=0.08075$.

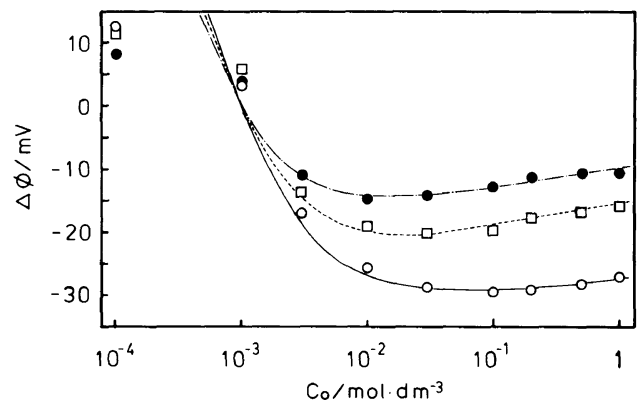

Figure 6. Membrane potential as a function of $\mathrm{NaCl}$ concentration, $C_{0}$, for the BSA-PMLG membrane before injection of L-alanine $(O)$, the BSA-PMLG membrane after injection of L-alanine (O), and the BSA-PMLG membrane at the same $\mathrm{pH}$ after injection of L-alanine by $\mathrm{N}_{2}$ bubbling ( $\square$ ). Solid line, broken line and dash-dot-line are calculated from eq 2 with $C_{x} / K$ and $U$ shown in Table $\mathrm{I}$.

membrane.

\section{Membrane Potential}

The membrane potential $(\Delta \phi)$ of the BSA-PMLG membrane before the injection of the substrate and after the injection of the substrate in equilibrium was measured as a function of $C_{0}$ at constant $C_{1}=10^{-3} \mathrm{~mol}$ $\mathrm{dm}^{-3}$, and is shown in Figure 6. The membrane potential at the same $\mathrm{pH}$ after the injection of the substrate was also measured under $\mathrm{N}_{2}$ bubbling and is plotted in Figure 6. Three potential curves show convex po- 
tentials as a function of $C_{0}$ and give typical membrane potential curves as expected by the Teorell-Meyer-Sievers (TMS) theory. ${ }^{15-18}$ The TMS theory, which was derived from the Nernst-Planck equation, makes the assumptions that (a) all the charges are considered to be point charges and ionic dimensions are neglected, (b) all the charges are dispersed homogeneously in the membrane, (c) hydrostatic pressure gradients and volume movements of the fluid are regarded as negligible, (d) electroneutrality holds in any part of the membrane, (e) the anion and cation fluxes are equal in any part of the membrane and (f) the total membrane potential, $\Delta \phi$, is given as the sum of the Donnan potential and the diffusion potential and is expressed as:

$$
\begin{aligned}
\Delta \phi= & -\frac{R T}{Z F}\left\{\ln \frac{C_{1}\left[1+4 y_{0}^{2}\right]^{1 / 2}-\alpha}{C_{0}\left[1+4 y_{1}^{2}\right]^{1 / 2}-\alpha}\right. \\
& \left.+U \cdot \ln \frac{\left[1+4 y_{1}^{2}\right]^{1 / 2}-\alpha U}{\left[1+4 y_{0}^{2}\right]^{1 / 2}-\alpha U}\right\}
\end{aligned}
$$

where $U=\left[\omega_{+}-\omega_{-}\right] /\left[\omega_{+}+\omega_{-}\right], \omega_{+}$and $\omega_{-}$ are the mobilities of the cation and the anion, $y_{0}=K \cdot C_{0} / C_{x}, y_{1}=K \cdot C_{1} / C_{x}, C_{x}$ is the effective fixed charge concentration, $K$ is the thermodynamic partition coefficient, ${ }^{11,15,19} \alpha$ has a value of +1 or -1 when the membrane is positively or negatively charged $(\alpha=+1$ in this study), $Z$ is the valence of the ion $(Z=1$ in this study), and $R, T$, and $F$ have the conventional meanings. Equation 2 indicates that the membrane potential is functions of salt concentration (i.e., $C_{0}$ and $\left.C_{1}\right), C_{x} / K$ and $U$.

Curve fitting of the experimental $\Delta \phi$ to eq 2 by adjusting $C_{x} / K$ and $U$ was performed by means of a nonlinear regression method
(Marquardt method). ${ }^{22}$ The membrane potential at $10^{-4} \mathrm{moldm}^{-3}$ was ignored in the curve fitting procedures. Since the electrical resistance of the BSA-PMLG membrane is too high at $10^{-4} \mathrm{moldm}^{-3}$ of $\mathrm{NaCl}$ solution because of low concentration of an electrolyte in the membrane, we cannot get precise value of the membrane potential. The $C_{x} / K$ and $U$ values for the BSA-PMLG membrane thus obtained are summarized in Table I. It is found that $\Delta \phi$ calculated by the TMS theory satisfactorily explains the experimental $\Delta \phi$ before the injection of substrate $(\Delta \phi$ (before)), $\Delta \phi$ after the injection of substrate $(\Delta \phi($ after $))$ and $\Delta \phi$ before the injection of substrate on the same $\mathrm{pH}$ after the injection of substrate which is obtained under $\mathrm{N}_{2}$ bubbling $\left(\Delta \phi\left(\mathrm{N}_{2}\right.\right.$ bubbling)) in Figure 6.

\section{Theoretical and Experimental Shifts}

The apparent shift in the membrane potential caused by the injection of substrate into a permeation cell $\left(\Delta \Delta \phi_{\mathrm{app}}\right)$ is represented by

$$
\Delta \Delta \phi_{\text {app }}=\Delta \phi(\text { after })-\Delta \phi(\text { before })
$$

$\Delta \Delta \phi_{\text {app }}$ values calculated by eq 2 and 3 with $C_{x} / K$ and $U$ found in Table $\mathrm{I}$ are plotted in Figure 7 together with $\Delta \Delta \phi_{\text {app }}$, which was obtained experimentally. The theoretical shifts were found to explain the experimental results satisfactorily.

The intrinsic shift in the membrane potential caused by the binding of the substrate to BSA $\left(\Delta \Delta \phi_{\text {int }}\right)$ is represented by

$$
\Delta \Delta \phi_{\text {int }}=\Delta \phi(\text { after })-\Delta \phi\left(\mathrm{N}_{2} \text { bubbling }\right)
$$

The $\Delta \Delta \phi_{\text {int }}$ values calculated by eq 2 and 4

Table I. Membrane potential parameters for BSA-PMLG membranes before and after the injection of L-alanine

\begin{tabular}{cccccc}
\hline Membrane & $C_{\mathrm{s}} / \mathrm{mol} \mathrm{dm}^{-3}$ & $\mathrm{pH}$ & $C_{x} K^{-1} / \mathrm{mol} \mathrm{dm}^{-3}$ & $U$ & Comments \\
\hline BSA-PMLG & 0 & 5.48 & 0.00325 & 0.0291 & \\
BSA-PMLG & 0 & 5.89 & 0.00240 & $0.0638 \quad$ Under N $_{2}$ bubbling \\
BSA-PMLG & 0.06 & 5.89 & 0.00167 & 0.0574 &
\end{tabular}




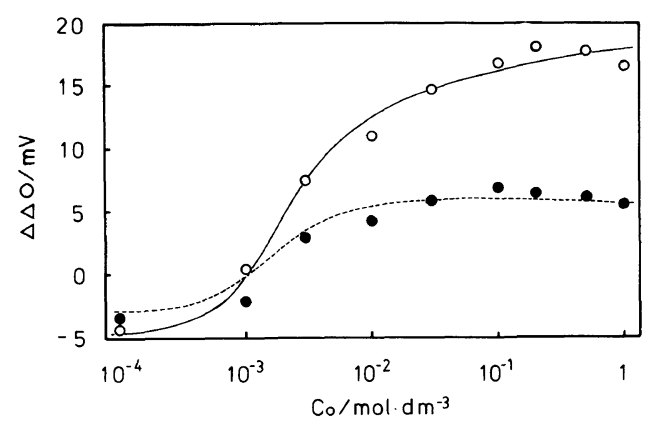

Figure 7. Apparent shifts in the membrane potential $(O)$ and intrinsic shifts in the membrane potential $(O)$ as a function of $C_{0}$ for the BSA-PMLG membrane at $C_{1}=$ $1.0 \mathrm{mmol} \mathrm{dm}^{-3}, C_{\mathrm{s}}=0.06 \mathrm{~mol} \mathrm{dm}{ }^{-3}$ and $37^{\circ} \mathrm{C}$. Solid line and broken line are calculated from eq $2-4$ with $C_{x} / K$ and $U$ shown in Table $I$.

with $C_{x} / K$ and $U$ found in Table I are also plotted in Figure 7 together with $\Delta \Delta \phi_{\text {int }}$, which was also obtained experimentally. These theoretical curves were also found to explain the experimental intrinsic shifts satisfactorily.

\section{Recognition of Substrates}

Several substrates other than L-alanine were also investigated as substrates injected into the cell in this study. Figure 8 shows the changes in the membrane potential upon the injection of D-alanine, L-alanine, L-tryptophan, and L-isoleucine at $C_{\mathrm{s}}=0.01 \mathrm{M}$. The potential response caused by the injection of each substrate shows the individual and characteristic curves depending on the substrate in the figure.

Table II summarizes the intrinsic shifts in the membrane potential, $t_{1 / 2}$ and $t_{3 / 4}$ caused by the injection of various substrates for the BSA-PMLG membrane. The data presented in Table II are averages of $4-6$ measurements and the standard deviation of $t_{3 / 4}$ is calculated to be $0.43 \mathrm{~min}$ in this study. $t_{1 / 2}$ indicates the time which shows half of the shift of $\Delta \Delta \phi_{\mathrm{app}}$ and $t_{3 / 4}$ indicates the time which shows $75 \%$ of the shift of $\Delta \Delta \phi_{\mathrm{app}}$. The intrinsic shifts in the membrane potential were observed to increase in the following order at $C_{\mathrm{s}}=0.01 \mathrm{M}, \mathrm{D}$-glucose $=$ methyonine $=0$
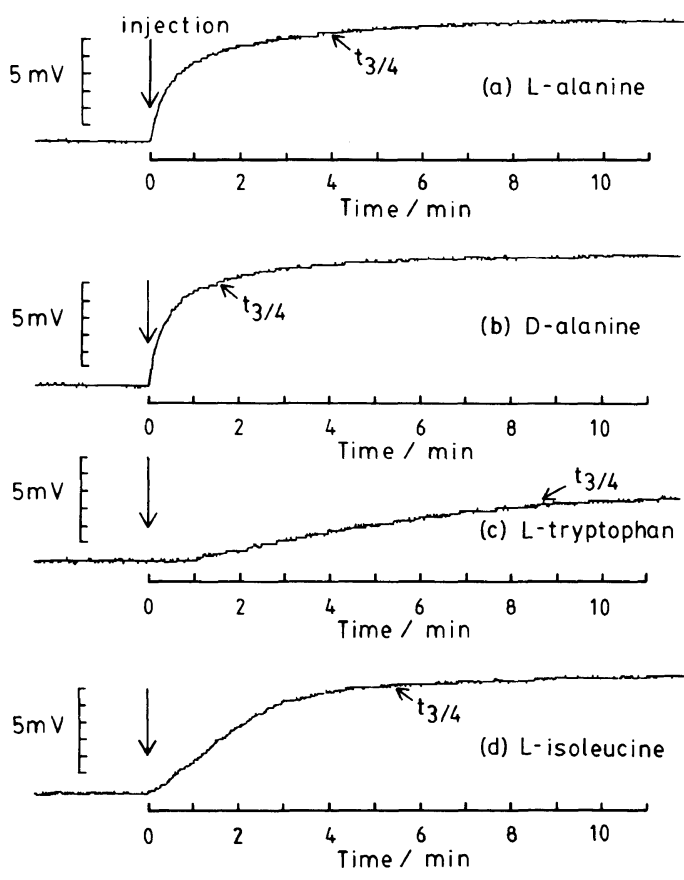

Figure 8. Time course of the membrane potential change on the injection of (a) L-alanine, (b) D-alanine, (c) L-tryptophan and (d) L-isoleucine in the BSA-PMLG membrane at $C_{0}=0.1 \mathrm{~mol} \mathrm{dm}^{-3}, C_{\mathrm{s}}=0.01 \mathrm{~mol} \mathrm{dm}^{-3}$ and $37^{\circ} \mathrm{C}$.

Table II. $t_{1 / 2}, t_{3 / 4}$, and $\Delta \Delta \phi_{\text {int }}$ induced by various amino acid for BSA-PMLG membrane at $37^{\circ} \mathrm{C}$

\begin{tabular}{|c|c|c|c|c|}
\hline \multirow{2}{*}{ Substrates } & $C_{\mathrm{s}}$ & $\Delta \Delta \phi_{\mathrm{int}}$ & $t_{1 / 2}$ & $t_{3 / 4}$ \\
\hline & M & $\mathrm{mV}$ & $\min$ & $\min$ \\
\hline \multirow[t]{6}{*}{ L-Alanine } & 0.001 & 0.08 & 0.30 & 0.95 \\
\hline & 0.005 & 0.62 & 0.65 & 1.9 \\
\hline & 0.010 & 2.61 & 1.25 & 4.0 \\
\hline & 0.030 & 5.63 & 0.70 & 3.8 \\
\hline & 0.060 & 7.51 & 0.78 & 3.8 \\
\hline & 0.100 & 8.96 & 1.7 & 5.5 \\
\hline D-Alanine & 0.010 & 3.19 & 0.45 & 1.6 \\
\hline L-Tryptophan & 0.010 & 1.62 & 4.9 & 8.8 \\
\hline D-Tryptophan & 0.010 & 2.10 & 4.6 & 8.5 \\
\hline \multirow[t]{2}{*}{ L-Serine } & 0.010 & 1.93 & 0.50 & 2.2 \\
\hline & 0.030 & 1.91 & 0.75 & 2.7 \\
\hline D-Serine & 0.010 & 1.49 & 0.45 & 1.8 \\
\hline L-Isoleucine & 0.010 & 2.45 & 2.8 & 5.2 \\
\hline L-Methyonine & 0.030 & 0.0 & - & - \\
\hline \multirow[t]{2}{*}{ D-Glucose } & 0.010 & 0.0 & - & - \\
\hline & 0.030 & 0.0 & - & - \\
\hline
\end{tabular}


$<$ D-serine $<$ L-tryptophan $<$ L-serine $<$ Dtryptophan $<$ isoleucine $<$ L-alanine $<$ D-alanine. Therefore, alanine, which shows the highest intrinsic shifts among the amino acids, was selected as the injected substrate for the observation of shifts in the membrane potential presented in Figures 2-7.

Data for a non-steady state $\left(t_{1 / 2}\right.$ and $t_{3 / 4}$ in this study) are sometimes good information for the recognition of substrates. We already reported that the concentration of multicomponent ions could be successively estimated by analysing the permeation of ions through a poly(vinyl alcohol) membrane at the non-steady state $^{20}$. Furthermore, the concentration of D-glucose and L-ascorbic acid in the cell was simultaneously estimated from current curves generated by immobilized glucose oxidase and ascorbic oxidase membranes at the non-steady state ${ }^{21}$.

The parameter $t_{3 / 4}$ should be better than $t_{1 / 2}$ in this study, because the initial change in the membrane potential is mainly caused by the $\mathrm{pH}$ change in the cell (see Figure 2). It is found in Table II that $t_{3 / 4}$ increases in the following order at $C_{\mathrm{s}}=0.01 \mathrm{M}$ : D-alanine $<$ serine $<\mathrm{L}-$ alanine $<$ tryptophan. The $t_{3 / 4}$ of D-alanine is found to be less than the $t_{3 / 4}$ of L-alanine, since the standard deviation of $t_{3 / 4}$ is calculated to be $0.43 \mathrm{~min}$. It is, therefore, suggested that the parameter $t_{3 / 4}$ can recognize the isomer of amino acid injected into the cell. It is known that both L-tryptophan and D-tryptophan bind to serum albumin on site $\mathrm{II}^{14}$. The $t_{3 / 4}$ for L-tryptophan gives the same value of the $t_{3 / 4}$ for D-tryptophan within experimental error in Table II. It is suggested that the binding site of L-tryptophan may be the same binding site of D-tryptophan from Table II, of which results correspond to the work of previous investigator $^{14}$ in a solution system. The $t_{3 / 4}$ is found to show the characteristics of each amino acid.

Potential curves at the non-steady state and the $t_{3 / 4}$ caused by the injection of substrates probably reflect the binding constant of substrates and specificity of binding sites on
BSA in the membrane potential measurements; however, the binding constant and binding sites of amino acid except tryptophan have not yet been reported.

From Table II, the results suggest that it may be possible to extract qualitative and quantitative information by combining a $\Delta \Delta \phi_{\text {int }}$ and $t_{3 / 4}$ to obtain a unique data pair which identifies a particular amino acid present at a certain concentration.

Acknowledgement. We are grateful to Dr. M. Iwatsuki and Dr. Y. Miyachi (Ajinomoto Co., Inc.) for their helpful suggestions. This research was partially supported by Sasakawa Scientific Research Grant (No. 4-006K) in the Japan Science Society from the Japan Shipbuilding Industry Foundation.

\section{REFERENCES}

1. A.M. Monnier, J. Membrane Sci., 2, 49 (1977).

2. K. Kimura and L. M. Beidler, J. Cell Comp. Physiol., 58, 131 (1961).

3. T. Nomura and K. Kurihara, Biochemistry, 26, 6141 (1987).

4. M. Montal and P. Meuller, Proc. Natl. Acad. Sci. U.S.A., 69, 3561 (1972).

5. T. Shinbo, M. Sugiura, and N. Kamo, Anal. Chem., 51, 100 (1979).

6. R. Tor and A. Freeman, Anal. Chem., 58, 1042 (1979).

7. A. Friboulet and D. Thomas, Biophys. Chem., 16, 153 (1982).

8. R. H. William and H. B. Halsall, Anal. Chem., 51, 100 (1979).

9. M. Aizawa, S. Kato, S. Suzuki, Y. Nagamura, R. Shinohara, and I. Ishiguro, Kobunshi Ronbunshu, 34, 813 (1977).

10. A. Higuchi, S. Ogawa, and T. Nakagawa, J. Chem. Soc., Faraday Trans., 87, 695 (1991).

11. A. Higuchi, S. Chida, and T. Nakagawa, J. Chem. Soc., Faraday Trans., 87, 2723 (1991).

12. D.E. Koshland, Jr. and K.E. Neet, Ann. Rev. Biochem., 37, 359 (1968).

13. U. Kragh-Hansen, Pharmacol. Rev., 33, 17 (1981).

14. U. Kragh-Hansen, Biochem. J., 273, 641 (1991).

15. H.U. Demisch and W. Pusch, J. Colloid Interface Sci., 69, 247 (1979).

16. A. Higuchi and T. Iijima, J. Appl. Polym. Sci., 31, 419 (1986).

17. T. Teorell, Proc. Soc. Exp. Biol. Med., 33, 282 (1935). 


\section{Recognition of Amino Acids}

18. K.H. Meyer and J.F. Sievers, Helv. Chim. Acta, 19, 64 (1936).

19. A. Higuchi and T. Nakagawa, J. Chem. Soc., Faraday Trans. 1, 85, 3609 (1989).

20. A. Higuchi, T. Katoh, and T. Nakagawa, J. Chem.
Soc. Faraday Trans. 1, 85, 127 (1989).

21. A. Higuchi and T. Nakagawa, Bull. Chem. Soc. Jpn., 63, 209 (1990).

22. K. Tone, "Basic, Play-micon Series 1" (in Japanese), Baihu-do, Tokyo, 1981, p 137. 